\title{
Seroprevalence of TORCH in women with spontaneous abortion and stillbirth, in Asmara, Eritrea
}

\author{
Elias T. Adgoy ${ }^{1}$, Mohammed Elfatih ${ }^{2}$, Banan Elhadi ${ }^{2}$, Habtesillasia Zerizgie ${ }^{3}$, Salih M. Said ${ }^{4}$, Freweyne Tekle ${ }^{4}$, Zeccarias \\ Andemariam $^{5}$
}

\author{
AFFILIATION \\ 1 Department of Community Medicine and Primary Health Care, Orotta \\ College of Medicine and Health Sciences, Asmara, Eritrea \\ 2 Department of Microbiology, Orotta College of Medicine and Health \\ Sciences, Asmara, Eritrea \\ 3 Department of Obstetrics and Gynaecology, Orotta College of Medicine \\ and Health Sciences, Asmara, Eritrea \\ 4 Ministry of Health, National Laboratory, Asmara, Eritrea \\ 5 Mai-Nefhi College of Science, Himbrti, Eritrea
}

\section{CORRESPONDENCE TO}

Elias T. Adgoy. Orotta Department of Community Medicine and Primary Health Care, Orotta College of Medicine and Health Sciences, Asmara, Eritrea. E-mail: eliasteages@gmail.com

\section{KEYWORDS}

TORCH, pregnancy, abortion, stillbirth, IgG, seroprevalence

Received: 3 May 2020, Revised: 9 August 2020,

Accepted: 30 September 2020

https://doi.org/10.18332/popmed/128008
(Serum), a prevalence of 0\% was found for seropositivity for anti-toxoplasma gondii IgG, HIV, and anti-herpes simplex IgG, whereas a prevalence of $2.27 \%$ was found for anti-rubella virus IgG and $2.27 \%$ for anti-cytomegalovirus IgG. The study findings showed no association between age and the current miscarriage/abortion, whereas a weak association $(p=0.96)$ between previous and current miscarriage/abortion was observed.

CONCLUSIONS The present study prevalences are very low compared to those of other studies. The study results predict a chance of having an abortion/miscarriage in the case of a previous abortion. We recommend that a countrywide survey be conducted on pregnant women who attend antenatal clinic during pregnancy.

ABBREVIATIONS ANC: antenatal clinic, BOH: bad obstetric history, CMV: cytomegalovirus virus, G: gestation, HIV: human immunodeficiency virus, HSV: herpes simplex virus, IgG: Immunoglobulin G, OMNRTH: Orotta Maternity National Referral Teaching Hospital, TORCH: Toxoplasma gondii, other diseases (HIV, syphilis, and measles), rubella, cytomegalovirus and herpes simplex virus, VZV: varicella zoster virus

faeces, during delivery; and during the neonatal period (postpartum) through breastfeeding, blood transfusion, and nosocomial. These infections are usually associated with some complication that becomes evident either from the maternal or fetal side, during pregnancy, after delivery, or at a later stage ${ }^{1}$. Toxoplasma gondii, others (HIV, syphilis, and 
measles), rubella, cytomegalovirus and herpes simplex virus 1 and/or 2 are a group of infectious diseases that are known as TORCH. These preventable infectious diseases are a public health problem because they cause maternal and neonatal morbidity, disability, and mortality. TORCH can adversely affect a pregnant woman and her fetus. The newborns of pregnant women who are infected with these diseases may have birth defects. Infections that are caused by TORCH are the major causes of bad obstetric history $(\mathrm{BOH})^{2}$.

If a pregnant woman is infected in the first trimester, the risks are severe. The general symptoms of the disease include: premature birth, neurological abnormalities, growth retardation, damage to the eyes, liver, heart and ear, also bone lesions, hydrocephaly, nanocephaly, seizer and psychomotor retardation. Pregnancy is a normal process in human beings, despite its termination before certain months particularly before 21 gestational weeks, which is considered as an abortion and attributed to a number of factors that interrupt the pregnancy's continuity in human reproduction ${ }^{1,2}$.

The interruption and discontinuity of pregnancy can happen due to many factors that include genetic, uterine abnormalities, endocrine and immunological dysfunctions, infectious agents, environmental pollutants, psychogenetic factors, and endometriosis. Infections that are caused by Toxoplasma gondii, rubella, cytomegalovirus and herpes simplex are major causes of pregnancy loss in humans.

During pregnancy, if any woman is infected with the above, the risk of a child born with serious birth defects and/or illness, miscarriage or stillbirth increases proportionally. A study that was conducted on abortion cases looking at the influence of TORCH infections in a first trimester miscarriage revealed a prevalence of $50.7 \%, 11.3 \%, 28.2 \%$ and $59.2 \%$ for T. gondii, rubella, CMV and HSV 1 and 2, respectively. Another hospitalbased study on pregnant women who were attending antenatal clinic during their first trimester at Maternity and Children's Hospital in Makkah, Saudi Arabia, also indicated a prevalence of $35.6 \%$ with Toxoplasma IgG antibodies, $92.1 \%$ with CMV, 93.3\% with rubella, $90.9 \%$ with HSV 1, 27.1\% with HSV 2, 74.4\% with VZV and $0 \%$ for HIV $1 \& 2$ antibodies ${ }^{3}$. Another prospective study that was conducted in 64 pregnant mothers in India also documented a prevalence of $26.56 \%, 76.56 \%, 85.93 \%$ and $53.12 \%$ for seropositivity of IgG for Toxoplasma, rubella, CMV and HSV, respectively ${ }^{4}$. A study on TORCH profile in patients with bad obstetric history in India also showed a prevalence of Immunoglobulin $\mathrm{G}$ antibodies of $20.93 \%, 29.06 \%, 23.25 \%$ and $18.60 \%$ for Toxoplasma, rubella, CMV and HSV-2, respectively 5 . Therefore, the present study was conducted to assess the magnitude of the prevalence of TORCH in women who had an abortion or stillbirth, to assist in managing the problem.

\section{METHODS}

A laboratory-based cross-sectional study on the frequency and associated risk factors for the prevalence of TORCH was conducted from 28 September to 30 November 2018. The study included 44 women aged 18-45 years who were admitted at OMNRTH, in Asmara, Eritrea, due to spontaneous abortion or stillbirth, whereas women with induced abortion (therapeutic/criminal abortions) and other diseases (HIV, syphilis, and measles) were excluded. The study obtained permission and an approval from the $\mathrm{MOH}$ ethical and research committee, and Orotta National Referral Maternity Teaching Hospital, and consent was obtained from women with spontaneous abortion or stillbirth.

From each woman, $3 \mathrm{~mL}$ of venous blood was collected in a container with aseptic technique. IgG antibodies against Toxoplasma gondii, rubella, cytomegalovirus and herpes simplex were detected by IgG Combo Rapid Test Cassette (Serum), which is a rapid chromatographic immunoassay that is used for the qualitative detection of these antibodies, demonstrating an overall accuracy of $97.8 \%$ for Toxoplasma gondii, $99.2 \%$ for rubella, $99.0 \%$ for CMV and $99.2 \%$ for HSV 1 and 2 . The collected data were analyzed descriptively and for any associations by $\chi^{2}$ test using SPSS version 25 software.

\section{RESULTS}

\section{Sociodemographic characteristics}

The study participants had a mean age of 29.3 years ( $\mathrm{SD}=5.6)$. The majority (86\%) of the mothers were married and were of Christian Orthodox religion (84\%). Almost 91\% were of Tigrigna ethnic group. Almost all the mothers $(97.7 \%)$ who participated in the study, except one $(2.3 \%)$, were non-smokers and had no smoking history (Table 1).

\section{Obstetric history of the study participants}

All study participants had no history of ectopic pregnancy.

Table 1. Sociodemographic characteristics of the study participants, Eritrea $(\mathrm{N}=44)$

\begin{tabular}{l|c|c|}
\hline Variable & n & $\%$ \\
\hline Age (years) & & \\
\hline 20 & 1 & 2.3 \\
$20-24$ & 10 & 22.7 \\
$25-29$ & 10 & 22.7 \\
$30-34$ & 14 & 31.85 \\
$35-39$ & 9 & 20.5 \\
Marital status & & \\
Married & 38 & 86.3 \\
Living together & 1 & 2.3 \\
Divorced & 1 & 2.3 \\
Single & 4 & 9.1 \\
Religion & & \\
Orthodox & 37 & 84.1 \\
Catholic & 3 & 6.8 \\
Protestant & 1 & 2.3 \\
Muslim & 3 & 6.8 \\
& & Continued
\end{tabular}




\section{$\%$}

\begin{tabular}{|l|r|r|}
\hline Variable & n & $\%$ \\
\hline Ethnic group & & \\
\hline Tigrigna & 40 & 90.9 \\
Tigre & 3 & 6.8 \\
Saho & 1 & 2.3
\end{tabular}

\section{Educational level}

$\begin{array}{lrr}\text { Primary school } & 8 & 18.2 \\ \text { Junior school } & 12 & 27.3 \\ \text { Secondary school } & 20 & 45.4 \\ \text { College and above } & 4 & 9.1 \\ \text { Participants' occupation } & & \end{array}$

\section{Participants' occupation}

$\begin{array}{lrr}\text { Housewife } & 29 & 65.9 \\ \text { Civil servant } & 4 & 9.1 \\ \text { Military/National service } & 1 & 2.3 \\ \text { Government employee } & 2 & 4.5 \\ \text { Trader or merchant } & 2 & 4.5 \\ \text { Self-employed } & 2 & 4.5 \\ \text { Commercial sex worker } & 1 & 2.3 \\ \text { Other } & 3 & 6.8\end{array}$

\section{Partners' occupation}

Farmer

1

Military/National service

34.1

Government employee

20.4

Trader or merchant

11.4

Self-employed

15.9

Unemployed

Other

13.6

Monthly income (Nkf)*

$\begin{array}{lrr}\leq 500 & 5 & 11.4 \\ 501-1000 & 16 & 36.4 \\ 1001-1500 & 6 & 13.6 \\ 1501-2500 & 8 & 18.2 \\ >2500 & 9 & 20.4\end{array}$

\section{Smoking in the past year}

\begin{tabular}{lrr} 
Yes & 1 & 2.3 \\
No & 43 & 97.7 \\
$\begin{array}{l}\text { Currently smoking or use of } \\
\text { tobacco }\end{array}$ & \\
\hline Yes & & \\
No & 1 & 2.3 \\
\hline
\end{tabular}

*Nkf: 100 Eritrean Nakfa about 6.7 US\$.

The majority of the mothers had a previous history of miscarriage or abortion, and $41 \%, 18 \%, 7 \%$ and $2 \%$ had experienced a miscarriage or abortion one time, two, three or four times, respectively. Of the mothers, $97.7 \%$ had no history of multiple gestations (Table 2).

\section{Serological test}

All of the 44 mothers with pregnancy loss, who were tested for the four IgG antibodies, were found to have $0 \%$ IgG seropositivity for Toxoplasma gondii, HIV and herpes simplex. In this study only two mothers were found to be IgG seropositive; one for rubella virus and another for cytomegalovirus (Table 3).

\section{Diagnosis or pregnancy outcome}

In all, $43 \%(n=19)$ of the mothers had a complete abortion, whereas the remaining $29.5 \%(n=13), 18.2 \%(n=8), 4.6 \%$ $(n=2)$ and $4.6 \%(n=2)$, were diagnosed as cases of incomplete

\section{Table 2. Obstetric history of the study participants,} Eritrea $(\mathrm{N}=44)$

\begin{tabular}{|c|c|c|}
\hline Variable & $\mathbf{n}$ & $\%$ \\
\hline \multicolumn{3}{|l|}{ Number of pregnancy } \\
\hline Primigravida & 11 & 25.0 \\
\hline Gravida 2 & 3 & 6.8 \\
\hline Gravida 3 & 5 & 11.4 \\
\hline Gravida 4 & 9 & 20.4 \\
\hline Gravida 5 & 8 & 18.2 \\
\hline Gravida 6 & 4 & 9.1 \\
\hline Gravida 7 & 4 & 9.1 \\
\hline \multicolumn{3}{|l|}{ Ectopic pregnancy } \\
\hline History of ectopic pregnancy & 0 & 0 \\
\hline \multicolumn{3}{|l|}{$\begin{array}{l}\text { Number of previous miscarriages } \\
\text { or abortions }\end{array}$} \\
\hline $\begin{array}{l}\text { No previous history of miscarriage } \\
\text { or abortion }\end{array}$ & 14 & 31.8 \\
\hline 1 & 18 & 40.9 \\
\hline 2 & 8 & 18.2 \\
\hline 3 & 3 & 6.8 \\
\hline 4 & 1 & 2.3 \\
\hline \multicolumn{3}{|l|}{ Number of deliveries } \\
\hline 0 & 12 & 27.3 \\
\hline 1 & 2 & 4.5 \\
\hline 2 & 14 & 31.8 \\
\hline 3 & 6 & 13.6 \\
\hline 4 & 5 & 11.4 \\
\hline 5 & 3 & 6.8 \\
\hline 6 & 2 & 4.5 \\
\hline \multicolumn{3}{|l|}{ History of multiple gestations } \\
\hline Yes & 1 & 2.3 \\
\hline No & 43 & 97.3 \\
\hline
\end{tabular}


Table 3. IgG seropositivity of the cases of pregnancy loss of the study participants $(\mathrm{N}=44)$

\begin{tabular}{|c|c|c|c|c|}
\hline \multirow[t]{2}{*}{ Variable } & \multicolumn{2}{|c|}{ Positive } & \multicolumn{2}{|c|}{ Negative } \\
\hline & $\mathbf{n}$ & $\%$ & $\mathbf{n}$ & $\%$ \\
\hline \multicolumn{5}{|l|}{ Test } \\
\hline Anti-Toxoplasma gondii IgG & 0 & 0 & 44 & 100 \\
\hline HIV & 0 & 0 & 44 & 100 \\
\hline Anti-Rubella Virus IgG & 1 & 2.27 & 43 & 97.73 \\
\hline Anti-Cytomegalovirus IgG & 1 & 2.27 & 43 & 97.73 \\
\hline Anti-Herpes Simplex IgG & 0 & 0 & 44 & 100 \\
\hline
\end{tabular}

Table 4. Association between age and previous/current miscarriage or abortion

\begin{tabular}{|c|c|c|c|}
\hline \multirow[t]{2}{*}{ Variable } & Yes & No & \multirow[t]{2}{*}{$\mathbf{p}^{*}$} \\
\hline & n (\%) & n (\%) & \\
\hline \multicolumn{4}{|c|}{ Age (years) } \\
\hline$<30$ & $12(57.1)$ & $9(42.9)$ & 0.133 \\
\hline$\geq 30$ & 18 (78.3) & $5(21.7)$ & \\
\hline Total & $30(68.2)$ & $14(31.8)$ & \\
\hline
\end{tabular}

${ }^{*} \mathrm{p}<0.05$, based on $\chi^{2}$ test.

abortion, missed abortion, threatened abortion and stillbirth (one preterm and one full-term), respectively. The study findings showed no significant association between age and the current miscarriage/abortion (Table 4).

\section{DISCUSSION}

The study included 44 mothers who were admitted at Orotta maternity national referral and teaching hospital. The mothers who participated in the study had different obstetric histories of pregnancies from primigravida to a multigravida of seven. In our study, the incidence of miscarriage was found to be: $2.3 \%$ for those aged $<20$ years; $22.7 \%$ aged $20-24$ years; $22.7 \%$ aged $25-29$ years; $31.85 \%$ aged $30-34$ years; and $20.5 \%$ aged $35-39$ years. These results are similar to those of a study 6 that reported the following incidences of miscarriage: $14.81 \%$ for $15-19$ years; $49.38 \%$ for $20-24$ years; $24.69 \%$ for $25-29$ years, and $11.1 \%$ for $30-34$ years ${ }^{6}$.

Toxoplasma gondii, HIV, rubella, cytomegalovirus and herpes simplex are the known causes of infections for a fetus and loss/termination of pregnancy. In Eritrea, no study to date has evaluated the seroprevalence of TORCH in women with spontaneous abortion or stillbirth. This study indicates a very low prevalence of Toxoplasma gondii, HIV, rubella, cytomegalovirus and herpes simplex IgG antibodies in women who had a miscarriage of a recent pregnancy (complete, incomplete, missed and/or threatening abortion) or stillbirth (pre-term or full-term). All of the 44 mothers with pregnancy loss, who were tested for the four IgG antibodies, were found to have a $0 \% \operatorname{IgG}$ seropositivity for Toxoplasma gondii, HIV and herpes simplex. In our study, only two mothers were found to be IgG seropositive; one for rubella and another for cytomegalovirus. The present study results are similar to those of studies in India, Turkey and Iraq, but the IgG seropositivity is found to be lower compared to the other studies ${ }^{7-10}$. These lower results may be attributed to the life style of Eritrean women, like consumption of properly heated and cooked food, and less contact with domestic animals. We found the prevalence of TORCH IgG to be much lower compared to the results of studies that were conducted in Saudi Arabia, India and Turkey ${ }^{3-6,11,12}$.

While the study was performed on a small sample size, the unique population and setting provide an interesting insight into TORCH in Eritrea. Despite the above, we recommend a countrywide survey among pregnant women who attend ANC during pregnancy.

\section{CONCLUSIONS}

Mothers who had pregnancy loss were found to have $0 \%$ seroprevalences of IgG antibodies for Toxoplasma gondii, herpes simplex and HIV infection, but very low $(2.27 \%)$ seroprevalence of IgG antibodies for rubella or cytomegalovirus.

\section{REFERENCES}

1. McClure EM, Dudley DJ, Reddy U, Goldenberg RL. Infectious causes of stillbirth: a clinical perspective. Clin Obstet Gynecol. 2010;53(3):635-645. doi:10.1097/grf.0b013e3181eb6620

2. Kishore J, Misra R, Paisal A, Pradeep Y. Adverse reproductive outcome induced by Parvovirus B19 and TORCH infections in women with high-risk pregnancy. J Infect Dev Ctries. 2011;5(12):868-873. doi:10.3855/jidc.1533

3. Ghazi HO, Telmesani AM, Mahomed MF. TORCH agents in pregnant Saudi women. Med Princ Pract. 2002;11(4):180182. doi:10.1159/000065813

4. Shrivastava G, Bhatambare GS, Patel KB. Seroprevalance of toxoplasma, rubella, CMV and HSV infection in pregnant women in central India. International Journal of Health System and Disaster Management. 2014;2(3):166-169. doi:10.4103/2347-9019.142202

5. Sadik MS, Fatima H, Jamil K, Patil C. Study of TORCH profile in patients with bad obstetric history. Biol Med (Aligarh). 2012;4(2):95-101. https://www.longdom.org/open-access/ study-of-torch-profile-in-patients-with-bad-obstetrichistory-0974-8369-4-165.pdf. Published July 1, 2012. Accessed August 9, 2020.

6. Sebastian D, Zuhara, KF, Sekaran, K. Influence of TORCH infections in first trimester miscarriage in the Malabar region of Kerala. Afr J Microbiol Res. 2008;2(3):56-59. doi:10.5897/AJMR.9000418

7. Surpam RB, Kamlakar UP, Khadse RK, Qazi MS, Jalgaonkar SV. Serological study for TORCH infections in women with bad obstetric history. J Obstet Gynecol India. 2006;56(1):41-43. 
https://www.jogi.co.in/jan_feb_2006/04_oa_serological.pdf. Accessed August 9, 2020.

8. Uyar Y, Balci A, Akcali A, Cabar C. Prevalence of rubella and cytomegalovirus antibodies among pregnant women in northern Turkey. New Microbiol. 2008;31(4):451-455. PMID:19123299.

9. Aynioglu A, Aynioglu O, Altunok ES. Seroprevalence of Toxoplasma gondii, rubella and Cytomegalovirus among pregnant females in north-western Turkey. Acta Clin Belg. 2015;70(5):321-324. doi:10.1179/2295333715Y.0000000021

10. Mohymen NA, Hussien A, Hassan FK. Association between TORCH agents and recurrent spontaneous abortion. Iraqi J Med Sci. 2009;7(4):40-46. https://www.iasj.net/iasj/ download/0bbffcc0f2821a82. Accessed August 9, 2020.

11. Altunal LN, Esen AB, Karagöz G, Yaşar KK. Seroprevalence of Toxoplasma Gondii, Rubella, and Cytomegalovirus Among Pregnant Refugees and Turkish Women: A Retrospective Comparative Study. South Clin Istanb Eurasia. 2018;29(4):235-239. doi:10.14744/scie.2018.66375

12. Saad KAO, Yousef N. Evaluation of Rubella, Toxoplasma gondii, and cytomegalovirus seroprevalences in women with miscarriage as adverse reproductive outcome in current pregnancy in ALBIYDA /LIBYA. IOSR J Pharm Biol Sci. 2016;11(5):81-84. doi:10.9790/3008-1105018184

ACKNOWLEDGEMENTS

We thank the members of the Serology Department at the National Health Laboratory of the State of Eritrea.

\section{CONFLICTS OF INTEREST}

The authors have completed and submitted the ICMJE Form for Disclosure of Potential Conflicts of Interest and none was reported.

\section{FUNDING}

All test kits for the mothers and procedures related to the research were funded by the research team.

\section{PROVENANCE AND PEER REVIEW}

Not commissioned; externally peer reviewed. 